
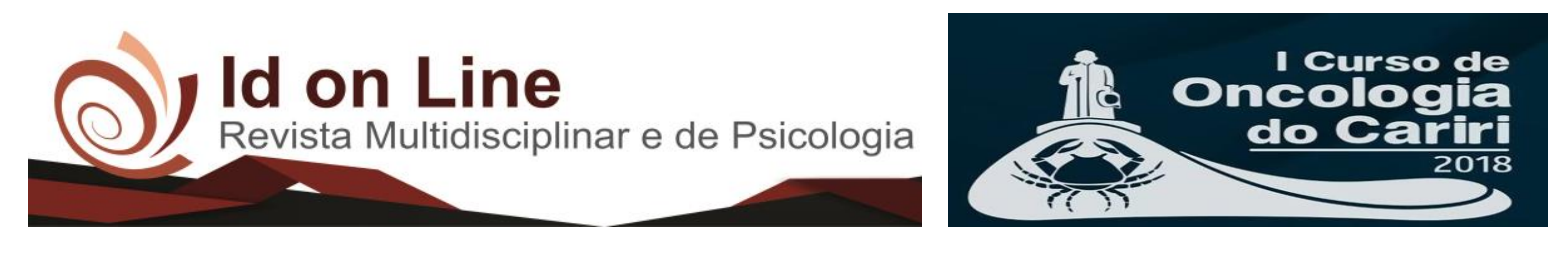

Resumo

\title{
MONITORIA DE SAÚDE E ESPIRITUALIDADE: UMA EXPERIÊNCIA TRANSFORMADORA NA LABUTA COM O CÂNCER
}

\author{
Karine Guiot Araújo ${ }^{1}$, Iago Sávyo Duarte Santiago ${ }^{1}$
}

Introdução: Os paradigmas da saúde vêm sofrendo mudanças, pois está sendo comprovada a necessidade de uma abordagem holística no cuidado dos pacientes, o que inclui aspectos físicos, psíquicos, sociais, políticos, culturais e espirituais. O processo de adoecimento nos pacientes oncológicos carrega um sentimento de finitude e morte, somados a vivência de dores e sofrimento. Então, a religião/espiritualidade torna-se nesse momento uma experiência que vai muito além da doença e traz um sentido na forma de enxergar a vida. Estudos já revelaram a associação entre a fé e um melhor enfrentamento do câncer, mostrando também uma melhoria significativa na qualidade de vida desses pacientes e diminuição das emoções negativas. Baseado nisso, a Monitoria de Saúde e Espiritualidade em Semiologia Médica, criada em 2016 no curso de medicina da Universidade Federal do Cariri, vinculada a Liga de Saúde e Espiritualidade do Cariri, começou em 2017 a desenvolver suas atividades práticas de anamnese espiritual em pacientes com câncer. Objetivo: Demonstrar através da aproximação com o paciente oncológico e com a sua experiência de dor e sofrimento, que a abordagem da espiritualidade pode ser transformadora durante o tratamento, tornando, assim, os estudantes mais preparados. Método: As atividades práticas da monitoria acontecem no Ambulatório de Terapia da Dor no Câncer e Cuidados Paliativos "Dra. Marinila Munguba Calderaro Macêdo", na cidade do Crato, Ceará, vinculado à Secretaria de Saúde desse Município. Os estudantes do $4^{\circ}$ semestre recebem o Treinamento Teórico-Prático em Anamnese Espiritual e aplicam esse método no Ambulatório da Dor, no qual, sob supervisão dos monitores e da médica anestesiologista especializada no controle da dor, realizam a anamnese e exame físico nos pacientes oncológicos. Resultados: Às vezes a morte em si não é o maior problema, mas sim o tempo que o paciente passa esperando ela chegar, felizmente, a atuação da monitoria no ambulatório tornou essa espera menos dolorosa, não só por tratar da espiritualidade, mas também pelo atendimento humanizado e completo. A consequência disso tudo é o impacto positivo causado na formação dos estudantes, na abordagem clínica dos profissionais da saúde envolvidos e principalmente na vida dos pacientes do ambulatório. Conclusão: Apesar de ainda existirem desafios e preconceitos, a monitoria tem quebrado paradigmas, implantando a abordagem correta na vivência dos estudantes e permitindo que os pacientes oncológicos sejam respeitados em sua integralidade, ampliando a dimensão do cuidar, que perde o seu foco na doença e ganha uma visão humana.

Palavras-chave: Câncer, Morte, Espiritualidade.

\footnotetext{
1 Acadêmico do curso de Medicina da UFCA ;
}

Autor Correspondente: karine_guiot@hotmail.com.

31 Id on Line Rev. Mult. Psic. V.12, N. 40. 2018 - ISSN 1981-1179 EDIÇÃO ESPECIAL: I CURSO DE ONCOLOGIA DO CARIRI / II JORNADA DE PESQUISA QUANTI-QUALITATIVA EM ONCOLOGIA. JUAZEIRO DO NORTE, 05 A 10 DE MARÇO DE 2018. Edição eletrônica em http://idonline.emnuvens.com.br/id 